\title{
Daily Judgement: Political News and Financial Markets
}

\author{
Michael Breen ${ }^{1}$, Iain McMenamin ${ }^{1}$, Michael Courtney $^{2}$, and Gemma McNulty ${ }^{3}$ \\ ${ }^{1}$ School of Law and Government \\ Dublin City University \\ ${ }^{2}$ Central Statistics Office, Ireland \\ ${ }^{3}$ Latin American and Caribbean Studies (LACS) Program \\ Northwestern University
}

\begin{abstract}
Political economists disagree about the extent to which markets monitor politics in advanced economies. Some argue that investors are interested in a handful of macroeconomic indicators, while others say that markets also watch political competition closely. We argue that political competition drives variation in the government bond market more than information about economic policy. Using a new automatic classifier, we code the content of millions of newspaper paragraphs about the UK from 1986 to 2012. We then test the impact of news on government debt. We find that political news is correlated with bond prices and that macroeconomic policy news is not. Our results suggest that the market passes daily judgement on politics, not merely cleaving to seldomreleased official statistics or focusing on occasional events like elections.
\end{abstract}

Key words: political economy; sovereign debt; economic policy; advanced economies; automatic content analysis

Acknowledgment: This research was supported by a Research Project Grant from the Irish Research Council.

\section{Corresponding author contact information:}

Dr. Michael Breen

Associate Professor of International Political Economy, School of Law and Government, Dublin 9, Ireland.

Tel. +353 (0)1 7006590, michael.breen@dcu.ie, https://sites.google.com/site/mhbreen/ 


\section{Introduction}

Government bonds are the principal measure of the financial markets' assessment of a government: the bond market 'passes a daily judgement on the credibility of [every government]' (Ferguson 2008, p. 69). Political economists disagree on how this judgement is made. Some argue that financial market constraints on government policy in advanced economies are strong-butnarrow; that is, investors are interested primarily in a narrow range of macroeconomic indicators (Afonso and Strauch 2007; Mosley 2003, 54). Essentially, this is because such economies are so stable and creditworthy that there is no real concern about their willingness and ability to pay. Others emphasise political risk, asserting that financial markets constantly monitor the uncertainty generated by political change, even in so-called advanced economies where there is little prospect of a sovereign default (Bernhard and Leblang, 2006). Both of these perspectives contribute to a much broader debate in political economy about the nature and extent of political risk (Bernoth, Von Hagen and Schuknecht 2004; Katzenstein 1985; Mosley 2003, 55; Rodrik 1997).

In this article, we argue that detailed information about political competition drives variation in the government bond market more than information about economic policy. Our argument rests on the premise that markets are concerned about political risk in advanced economies, and will react to a broad spectrum of information about politics. Previous studies have struggled to test this idea because the amount of information about politics is so vast. Without a daily measure of political competition, it is difficult to know whether there is indeed daily judgement. The advent of big data techniques provides us with an opportunity to address this gap. Drawing on these techniques, we develop an automatic classifier which we use to code millions of newspaper paragraphs about the UK between 1986 and 2012. 
We find that news about political competition is correlated with bond market activity, but that news about economic policy is not, in general, correlated with market activity. This is encouraging for scholars who take a broader view of political risk, as it suggests that markets constantly monitor the political arena in a highly advanced economy. Contrary to the strong-but-

narrow thesis, which argues that advanced economies have largely eliminated political risk (Mosley, 2003, 55), it shows that investors respond to the uncertainty generated by political change. Only in some circumstances, such as when greater central bank influence prevails, do we observe a stronger link between economic policy news and market behaviour. Though our results suggest that political risk is here to stay, our argument does not distinguish between different types of political risk, so we cannot say whether electoral risk, or another type of political risk, is the root cause of the relationships that we observe. In sum, our results suggest that while a government may have considerable room to manoeuvre, this is earned through daily judgement and not just a singular focus on the macro economy.

\section{Politics, Policy, and Markets: Which Information Matters?}

The literature on politics, policy, and financial markets varies enormously in terms of which information, and how much of it, is studied. It ranges from none, through very general, sticky variables, like constitutions, on through a variety of political events, to scholarship that engages directly with press releases and the media.

Economic historians and comparative political economists have emphasised institutions. This work has concentrated on differences amongst developing economies (Biglaiser and Staats 2012; Beaulieu et al. 2012, Archer et al. 2012, DiGiuseppe and Shea 2015), but has also been applied to stable, rich democracies (Rommerskirchen 2015, 2019, Breen and McMenamin 2013, Hallerberg and Wolf 2008). Others argued that political risk in developed economies largely 
belongs to history (Afonso and Strauch 2007, Mosley 2003, p. 54). Investors had lost interest in political differences, whether institutional or ideological, and cleaved to a narrow set of macroeconomic statistics, which indicated neither ability nor willingness to repay debt, but just the risk of a debt losing value to inflation (Mosley 2003, 69). By implication, then, governments that stuck to the macroeconomic orthodoxy were free to pursue partisan preferences in microeconomic policies, without fear of negative market reactions (Bernoth et al. 2004, Mosley 2003, p. 55).

Another strand of literature emphasises specific events, rather than general structures. Bernhard and Leblang (2006) argue that financial markets monitor the uncertainty generated by political change and adjust their investments accordingly. Many other researchers argue that a wider range of political events impact on financial markets (McMenamin, Breen and MuñozPortillo 2015, Jayachandran 2006, Vaaler et al. 2005). A range of papers also demonstrate that ideology matters to financial markets in developed countries. Sattler (2013), Fowler (2006), Bechtel (2009), Bechtel and Füss (2008) and Leblang and Mukherjee (2005) discover major partisanship effects of elections on stock markets. Much of the event-study literature is consistent with the institutional literature, in that the effect of events on financial volatility is held to be conditional on institutional arrangements.

Finally, there is research that investigates how markets react to the media, through which, after all, the vast majority of our political information comes. Mauro et al. take a relatively inductive approach by searching for the news associated with large changes in the spreads between the interest on emerging market debt and US bonds (2007, p. 61). Others have studied official releases of political (Bølstad and Elhardt 2015, Goldbach and Fahrholz 2011) and economic information (Almeida et al. 1998). Automatic content analysis has allowed much larger amounts 
of text to be coded and related to financial market developments. There are now many studies that leverage large amounts of text from many actors over a short period (Bølstad and Elhardt 2018, Bollen, Mao, and Zeng 2010) or from few sources over very long periods (Baker, Bloom and Davis 2016).

The literature tends to be partial, in the sense that individual articles tend to look at very specific events or time periods. ${ }^{1}$ This, of course, means that it is very difficult to judge the relative strength of arguments. The particular focus of much of the scholarship is a result of technical necessity. Manually gathered data must focus on a small number of observations. Even impressive recent empirical studies have not tended to exploit the full potential of new techniques. For example, the Economic Policy Uncertainty Index relies on a search for a handful of words (Baker, Bloom and Davis 2016). Regardless of technical or resource constraints, there has been no theoretical constraint to a more general approach to the study of politics and financial activity. In the next section, we present a general approach to conceptualising political competition, and show how it allows us to advance a new argument on the relative importance of political and macroeconomic policy news.

\section{Politics, Policy, and Markets: Theory and Hypotheses}

In testing the argument that political information is more influential than policy information, it is important to state our argument in a way which reflects the fast-moving world of financial markets.

\footnotetext{
${ }^{1}$ Recent work has had some success establishing long-term statistical relationships though in the opposite direction, from markets to politics. Hardie, Henderson, and Rommerskirchen (2019) illustrate the power of the bond market, showing that US presidential approval rates have followed US Treasury yields from 1961 to 2010.
} 
There is a substantial debate in political economy about how markets process information. We focus on the extent to which information can help investors gain an advantage over other market participants by using public information to anticipate price changes. Our argument is that information about political competition is an opportunity to gain insights into the future path of economic policy, and thus, economic outcomes. This approach is compatible with several theories of how markets process information, including the efficient market hypothesis and various behavioural approaches. The Efficient Markets Hypothesis states that relevant information is immediately incorporated into prices. Behavioural finance scholars emphasise the systematic irrationality of markets by drawing on psychological theory (Kahneman and Tversky 1979, McMenamin et al. 2016). Our analysis shows that markets react quickly to the volume of information about politics; it does not show that they react correctly or incorrectly. However, our contribution is to study which type of political information is important to market decisions, rather than how that information is processed. Thus, it is plausible that the correlations we present reflect immediate price adjustment but it is also plausible that these correlations reflect other types of immediate responses that could be characterised as market inefficiencies, including over-reactions (De Bondt and Thaler 1985) and herding behaviour (Shiller 1995). While our main contribution is to show that political news is the most important on average, averages can hide substantial variation in decision-making over-time. Thus, our findings are also consistent with market heterogeneity: the correlations we observe may be driven by different strategies among investors. We cannot tell if investors' expectations about their fellow market participants are well-founded or unrealistic (Scheinkman 2014). We cannot adjudicate in the ongoing battle between the advocates of efficient markets and behavioural biases. However, we do emphasise and find 
evidence to support what many scholars in both schools assume: that information matters on a dayto-day basis.

\section{Why Politics Matters, Almost Everyday}

There is a rich variety of political news, from the minutiae of local politics to historic national elections. As we have already mentioned, the literature on politics and financial markets shows that investors monitor national politics around important events such as elections (Bernhard and Leblang 2006, Sattler, 2013) and budgets (McMenamin et al.2015). However, existing studies have neglected a wide range of potentially relevant breaking news, such as cabinet collapses, reshuffles, resignations, and political corruption. This list is certainly not exhaustive but it illustrates the need for quantitative studies to move from studying isolated political events or episodes to studying politics as a continuous process. Since politicians are ultimately responsible for most economic policy decisions, investors should take a keen interest in which parties and politicians will establish superiority over others. Any type of political competition, whether interor intra-party, may provide insights into changes in economic policy. Some days, there will be little competition and investors will not have the opportunity to draw on politics to make bets on economic outcomes. Elections will undoubtedly provide the most information, primarily about the likely composition of the parliament and executive. Election results undoubtedly provide the most information about the likely composition of the parliament and therefore the future direction of policy, but there are many other sources of relevant information too.

At its most basic, our argument is that political competition determines political hierarchies, which in turn make policy decisions in relation to the national economy. These decisions have consequences, which are reflected in the macroeconomic indicators that summarise the impact of policy. Therefore, our first hypothesis is that variation in news about political 
competition is correlated with bond market activity to a greater extent than economic policy news. Of course, this hypothesis is at the highest level of generality. It says nothing about the specific dimensions of politics that markets track, whether ideology, poll numbers, programmatic outlook, or partisan divisions. Our assumption is that investors are interested in new information pertaining to all of these dimensions of politics and that the market price will reflect changes in the category of political information. Hypotheses at this level of generality are important yet have proven very challenging to test because we lack reliable daily measures of politics or economic policy over long periods of time.

\section{Macro and Microeconomic Policy News}

Given the widespread availability of macroeconomic data and the ubiquity of macroeconomic debate, the implications of national economic statistics will usually have been priced into the bond yield very quickly (Almeida et al. 1998). This reflects a broad consensus on what matters in macroeconomics and how it matters. Macroeconomic policy change is of more immediate consequence to bond markets, as it offers investors a chance to anticipate macroeconomic indicators. As a consequence, investors should closely monitor macroeconomic policy news and place their bets accordingly. However, the relationship between policy and outcomes is often unclear, or even downright controversial. Moreover, since the news itself tries to anticipate policy developments, the implications of news about macroeconomic policy for actual macroeconomic policy will also be unclear. So, policy uncertainty should be reflected in market activity. If markets are more sensitive to the immediate consequences of economic policy change, macroeconomic policy news should be associated with daily variation in bond markets. Thus, our second hypothesis is that the variation in macroeconomic policy news is associated with market activity. 
Microeconomic policy change is of less immediate consequence and indeed some studies claim that markets were indifferent to these policies in some advanced economies, at least until the outbreak of the global financial crisis (Mosely 2003). Therefore, our third hypothesis is that there should be a weaker relationship between microeconomic policy news and market activity, as markets focus on the more immediate opportunities from macroeconomic policy change.

All of these relationships (Hypotheses 1-3) should be dynamic. Markets, whether efficient or biased, do not formulate a theory and stick to it decade after decade. Taking context into account means adjusting to new information. While information and prices should be correlated, the exact nature of the correlation is expected to vary over time; economic policy will take centre stage in some general contexts, such as financial crises, and specific contexts, such as unexpected decisions by central banks; whereas political news will dominate in others, such as elections and turmoil in governing parties.

\section{Testing the argument}

To test these hypotheses, we use government bond and newspaper data relating to the United Kingdom. While not a representative case for understanding the phenomena that we are studying, the UK's unique combination of features make it an excellent test case for our argument. First, it is large enough to allay concerns that abrupt changes in interest rates are a function of market liquidity. Second, it is sufficiently autonomous: its independent central bank and floating exchange rate ensure that macroeconomic policy is a prominent feature of the domestic news agenda. Furthermore, it is not an obvious member of a peer-group like the Eurozone or the PIIGS, so investors will tend to evaluate UK government policy with less prejudice. Third, it is a most likely case for our political news hypothesis; its majoritarian political system is more likely to lead to 
substantial changes in the composition of parliament and the government. Therefore, reports about political competition in the UK should be associated with more volatile market reactions than elsewhere. Moreover, in the UK media it is much easier to distinguish between news about political competition and news about policy. This is supported by media systems theorists who argue that the coverage of politics is less policy-oriented in unconstrained political systems, which tend towards infotainment and portray politics as a game or sport (Hallin and Mancini 2004, p. 76, p. 279, p. 280-1; Strömbäck and Kaid 2008, p. 8). Moreover, the UK is home to the world's best regarded financial newspaper, The Financial Times (FT). The Financial Times can provide a comprehensive daily indicator of the information available to markets over a long time period. Tweets may move markets these days, but Twitter is obviously a recent innovation. The Bloomberg terminal has become the main conduit for market information over the last twenty-five years, although it would not have been used to convey news in the early years of our sample. Bloomberg terminals feed in news from a variety of sources. The default setting below the trading screen features articles from the Financial Times very prominently. In terms of the broad news agenda, Bloomberg and the Financial Times will tend to agree on whether the news of the day is, for an example, an election, or a Central Bank news conference. For news on a specific stock, traders will seek out more specialised sources, but the political and macroeconomic news that impacts on sovereign debt is shared across general financial news outlets like the Financial Times and Bloomberg. We now proceed to outline how we classified newspaper content.

\section{Automatic Content Analysis}

We measure the volume of different types of news by an automatic content analysis. We use supervised learning, according to which a computer induces an automatic classifier from a sample of manually-coded texts (Courtney et al. 2020, Manning et al. 2008, p. 236, Hillard, Purpura and 
Wilkerson 2007, p. 36). Supervised learning must meet three basic conditions in order to be meaningful. First, the categories must be valid measures of theoretical concepts. Second, humans should be able to reliably reproduce each other's coding. Third, the computer should be able to reliably reproduce the humans' coding. We address each challenge in turn.

We coded articles into macroeconomic policy news, microeconomic policy news, other policy news, and political competition (Figure S1 in Supplementary Information shows the decision tree we used). In coding policy news, we followed the Comparing Policy Agendas project, which is a large, collaborative manual coding project focused on the policy process that has been ongoing for over two decades (Baumgartner, Green-Pedersen, and Jones 2006). We followed their general definition of policy news as requiring some explicit reference to policy-makers or advocacy of policy change. We amalgamated their more detailed scheme into the basic theoretically-relevant categories of macro and micro-economic policy. We only coded policy news, so news about macroeconomic performance is not included. We were also careful to avoid news that was endogenous to financial market developments by excluding articles from the Companies and Markets section of the FT. This will often contain phrases such as, 'Markets rose today on news of the Chancellor's spending plans'. Political competition refers to the contest for power rather than what is done with that power. Our understanding of political competition is the same as the media studies literature on election coverage. Political competition refers to the 'game' of politics, including topics such as the 'horserace' for votes, leadership and personality, and strategy and tactics.

If the human input is unreliable, it is unclear what, if anything, algorithms are learning to reproduce. In our opinion, the absence of inter-coder reliability scores and unacceptably low intercoder reliability is a fundamental weakness of much of the literature on supervised learning. 
Indeed, many manual content analyses also neglect reliability. The small number of categories we coded reflects our determination to produce reliable data. Our level of analysis was also driven by reliability. Paragraphs are easier to code reliably, partly because a whole newspaper story will often contain more than one topic. We used Krippendorff's Alpha, the gold standard of inter-coder reliability, to assess our performance. Table 1 shows that our team was very close to the conventional score of 0.8 for highly reliable coding.

\section{[TABLE 1.]}

With a satisfactory level of inter-coder reliability, the team proceeded to code 3,901 paragraphs independently. Due to the limitations of the LexisNexis database through which we accessed the FT's archive, we adopted a hierarchical process of paragraph selection. In doing so, we drew random paragraphs from the newspaper; first we selected a random year, then a random article from that year, and finally a random paragraph from within the article. This included the possibility of the headline or highlighted text at the beginning of an article being selected. The paragraphs had a mean length of 57 words and a standard deviation of 44 words.

We then proceeded to develop a Support Vector Machine (SVM) automatic classifier that could reproduce our coding. This requires a training set of manually-coded paragraphs and a separate test set of manually-coded paragraphs. Learning is an inductive process in which several algorithms use the base rate of the categories in the training set and the words that distinguish each category to build a classifier.

We focused precisely on the data we are interested in by constructing separate classifiers for each category of interest (macroeconomic policy, microeconomic policy, and political 
competition). Each classifier generates a probability that a paragraph will be associated with the topic of interest. We use these probabilities as variables in our bond market analysis.

To train the classifiers, we divided the data into training and test sets. In total, 80 per cent of category $i$ paragraphs drawn from our manually coded paragraphs were used as training data and 20 per cent as test data. In the training set, half of the articles are coded as category $i$ and half as not category $i$. The fifty per cent that are not category $i$ are drawn from a larger pool of paragraphs reserved for training and are randomly selected from that pool. In the test set, paragraphs come from a separate pool of paragraphs amounting to twenty per cent of our manually coded paragraphs and are unseen by the classifier before classification begins. Therefore, the distribution of categories within the test set is a good representation of the variation in the full dataset.

The classifier was trained to recognise either category $i$ or anything else and was tested on the paragraphs not included in the training data. The algorithm outputs the equivalent of a probability for each category, rather than a discrete categorization. The resulting news category variables are the mean probability of all paragraphs in category $i$ on day $t$. Thus, a single paragraph may have a high probability of being associated with more than one category but the mean probability on day $t$ is an accurate estimate of the proportion of the FT that consists of a particular news category. More precisely, we use the mean probability of all paragraphs in category $i$ on day $t$ as an estimate of the proportion of the FT on day $t$ represented by category $i$.

Although we used probabilities in our bond market analysis, the accuracy of our classifiers is presented in Table 2 in terms of discrete categorization of category $i$ versus other. The resulting classifiers each achieved high levels of accuracy when distinguishing between category $i$ and the random sample of other paragraphs. In Table 2, 78 per cent of macroeconomic paragraphs were 
correctly identified by the macroeconomic classifier while 86 per cent of non-macroeconomic paragraphs were correctly classified as 'other'.

\section{[TABLE 2.]}

The FT is a global newspaper based in Britain. We are interested in the relationship between policy relevant information and UK government bonds. Thus, in addition to categorizing each paragraph of the newspaper for policy relevant information we also need to identify the country to which the paragraph relates. This is a named-entity-recognition task. We used a dictionary to meet this challenge.

First, we constructed a dictionary of proper names of 182 politicians, institutions, and offices. If at least one of the UK relevant entities is mentioned in a paragraph, the paragraph is assigned a UK entity code. Second, we developed and applied an n-gram check to take account of the different lengths of named entities. For example, 'Westminster' (1-gram) or 'David Cameron' (2-gram) should trigger a UK classification. However, it is necessary to check each combination of adjacent words against the dictionary list of entities up to 6 grams. As 'David Cameron' is a 2gram observation in the dictionary, single gram checks of 'David' and 'Cameron' would not trigger a UK code (Type I error) but does prevent any instance of 'David' triggering a UK code (Type II error). An n-gram checker is the only reasonable way to avoid these types of error.

Since we parse paragraph by paragraph, Type I error might occur when a paragraph is preceded and succeeded by paragraphs which correctly trigger a dictionary code but do not 
themselves include a named entity trigger. ${ }^{2}$ Thus, when an entity code is triggered, all succeeding paragraphs are assigned the same code, unless and until a non-UK entity code is triggered. We discard paragraphs preceding the paragraph with the first entity code in the document even though it might be as relevant to the UK as the paragraphs succeeding the first entity code. Paragraphs not assigned a country-code are also discarded, even if they were assigned a policy code. We now proceed to explain how we use this data to test our hypotheses.

\section{Modelling procedures}

Our argument asserts that the relationship between the markets and the media is dynamic and characterised by volatility. In other words, efficient markets do not implement a universal theory of political economy. Instead, they react to changing context. Therefore, we require a model that can account for dynamic relationships and the volatile nature of our variables. The Multivariate GARCH model (MGARCH) with the dynamic conditional correlation (DCC) estimator is appropriate for this challenge. The MGARCH DCC model relaxes a number of assumptions that are common in workhorse models in political science, such as unidirectional causality, constant correlation, and a focus on the conditional mean. By contrast, this model treats our variables as an endogenous system and assumes time-varying correlation, such that the importance of our media variables is not assumed to be constant over time but may vary as predictors of market sensitivity, and vice versa. As well as a focus on the conditional mean, the model illustrates relationships among the conditional variances and co-variances of our variables.

\footnotetext{
${ }^{2}$ Paragraphs in the FT's Home news section are assumed to be about the UK unless another country entity is present, whereafter the process we describe is initiated.
} 
Volatility is a central concern of finance and economics, as it affects levels of investment, security valuation, and is an important indicator for policy-makers.

The MGARCH DCC model can be written as a series of five equations. The complete model is described in Engle (2002). We focus on two of these equations as they correspond to the two dimensions of market sensitivity that we're interested in studying: the conditional mean and conditional variance. The first equation deals with the mean:

$$
y_{t}=C_{x t}+\varepsilon_{t}
$$

In this equation, $y_{\mathrm{t}}$ is an $m \times 1$ vector of dependent variables and $C$ is an $m \times k$ matrix of parameters. Thus, the conditional means of all of our news and market variables are modelled as a first-order vector autoregressive process. The conditional variance, or movement of the errors is also theoretically important, as it allows us to understand the dynamic correlation between market deviations and deviations in the news. In MGARCH DCC, the conditional variances and covariances of the errors follow an autoregressive moving-average structure. The error term from equation (1) above is modelled as follows:

$$
\varepsilon_{t}=H_{t}^{\frac{1}{2}} v_{t}
$$

$\mathrm{H}$ is the conditional covariance matrix. The diagonal elements of this matrix, $h_{i i, t}$ and $h_{j j, t}$, follow univariate GARCH processes, where $h$ is modelled as a function of the previous day's variance and the previous day's variance squared.

$$
\varepsilon_{t}=H_{t}^{\frac{1}{2}} v_{t}
$$

We are interested in the value of $p$, which is the conditional quasicorrelation of the standardised residuals from the MGARCH DCC model. Put simply, $p$ describes the co-movement 
and evolution of market and news deviations. Therefore, it is an excellent measure of market and news sensitivity. For the sake of simplicity, we will use the term co-movement to describe this quantity. However, it is important to stress that it is not a correlation coefficient in the traditional sense, as it takes into account the evolution and history of each variable.

In order to measure market prices we use the yield on ten-year UK government bonds against the 10 year US Treasury Note, otherwise known as the spread. ${ }^{3}$ This is the asset most closely associated with the British government. The data consist of all trading days from January 1986 to the end of 2012. Standard tests confirm the presence of volatility clustering; that is, large changes in UK returns tend to be followed by more large changes, and the same for small changes. ${ }^{4}$ Our model is estimated in first differences to account for non-stationarity. A Wald test rejects the null hypothesis of time-invariant conditional correlations, supporting our decision to model the conditional covariances as a MGARCH DCC process. $^{5}$

The rest of this section is organised as follows. We begin by describing the relationship between the conditional means of our variables and then move on to analyse the co-movement of markets and the media from 1986 to 2012. The trends in market and news activity support our

${ }^{3}$ Both the UK and US interest rate data are 10-year government bonds from Datastream.

${ }^{4}$ Inspection of the residuals confirms the need to model heteroscedasticity and further tests for non-stationarity suggest that we must use first order differencing.

${ }^{5}$ In this technique, the model reduces to MGARCH CCC when the adjustment parameters $\lambda 1=\lambda 2$ $=0$. We performed a Wald test which rejects the null hypothesis that $\lambda 1=\lambda 2=0$ at conventional levels, supporting our decision to use the DCC estimator and suggesting that the assumption of time-invariant conditional correlations is too restrictive for daily bond market and media data. 
emphasis on political competition: more variation in political news is associated with more variation in bond returns, and vice versa. Next, we discuss the impact of contextual change, namely budgets and elections. We find that many political episodes, especially elections, are associated with large increases in co-movement in bonds and news. We do not find such a general relationship between macroeconomic policy news and bonds. Finally, we consider the impact of Bank of England announcements in order to illustrate that there can be co-movement of macroeconomic policy news and bonds, especially when macroeconomic policy is insulated to a greater degree from political competition.

\section{Media-Market Dynamic Correlations}

Table 3 shows that daily changes in the mean level of our news variables are not associated with changes in UK bonds. The lack of market sensitivity to changes in the mean may be due to structural features of the news, such as predictable rises in coverage on days when it is expected that political and economic issues will be covered in more detail, or when new information is released as part of choreographed events like the publication of expert reports or new statistics. Indeed, a significant portion of political and policy news follows a set format that changes predictably. For example, Prime Ministers answer questions every Wednesday at noon when the House of Commons is sitting and their answers are often newsworthy. Given the structural features of the news, we move on to consider how deviations in and among our variables are potentially related, as they are potentially a more informative source of market sensitivity to political and policy news in the context of our study.

\section{[TABLE 3.]}


In Table 4, we describe the co-movement of the volatilities of UK bonds and the news. ${ }^{6}$ The daily co-movement of UK bonds and political news is statistically significant from 1986-2012 and as expected, more volatility in political news is associated with more volatility in bond returns, and vice versa. Investors seem to pay attention to news about political competition on a daily basis, not only around rare and important political events.

The daily co-movement of UK bonds and economic policy news is statistically insignificant. In particular, the weak association between macroeconomic policy and bonds undermines the argument that markets are concerned primarily with the immediate consequences of macroeconomic policy change, as they are more likely to focus on political developments further back in the causal chain, presumably, in order to generate high returns.

\section{[TABLE 4.]}

Of course, the estimated relationships are dynamic - single quasi-correlation coefficients like those presented above are only the beginning of how we can describe the association between the markets and the media. To elaborate, we extract a daily measure of co-movement from the above model. As expected, the average co-movement of political news and bond returns is positive: $\rho$ is

${ }^{6}$ Estimates from the univariate GARCH models that make up the MGARCH framework are not displayed, although all ARCH and GARCH terms are statistically significant and the overall model is a good fit, as indicated by the Wald test statistic and associated $p$ value. We have repeated this test using absolute Gilt yields in place of the spread and the results are broadly similar (see Table S3 in Supplementary Information). 
0.043 on average but varies from zero to a high of 0.45 with a standard deviation of 0.037 . The average co-movement of macroeconomic policy news and returns is 0.045 and varies from zero to 0.43 with a standard deviation of 0.042 . Microeconomic policy news co-movement exhibits a similar pattern. However, the level of coverage differs among the three types of news: microeconomic policy is the most frequently occurring type of news coverage on average at a mean daily probability of 0.424 , followed by macroeconomic policy at 0.358 , and political news at 0.246 . The comparatively greater proportion of economic policy coverage in our sample is to be expected as it consists of FT paragraphs, a newspaper that specialises in economic policy analysis. The broad trends in our descriptive statistics point toward frequent political and policy news coverage, and broadly consistent levels of co-movement, interspersed with episodes of extreme co-movement. In the next section, we investigate the circumstances under which co-movement between markets and the media change dynamically.

\section{[TABLE 5.]}

\section{Political context and the dynamics of the media and financial markets}

In this section we examine the dynamics of the relationship between the media and the market across different contexts and cases. The first context we consider is an election, which is essential in deciding the distribution of power. The second is a budget, which is the most important peacetime exercise of power. Elections are the key to political competition, while budgets are the key to macroeconomic policy. We expect an increase in co-movement around these different contexts, as markets and the media try to anticipate the composition of the legislature and taxing and spending in the forthcoming year. 
Our first model consists of budget and election dummy variables that measure one calendar month before the episode is concluded. The results, described in Table 5, show that, all else being equal, pre-election periods are associated with an increase in the co-movement of political news and bonds, and pre-budget periods are associated with an increase, albeit much smaller, in the comovement of macroeconomic policy and bonds. More specifically, an election period is associated with a large increase in co-movement representing 67.5 per cent of one standard deviation. The association between budgets and political news is not statistically significant. However, there is an association between budgets and macroeconomic policy news co-movement: a budget period represents co-movement of 11.9 per cent of one standard deviation. Interestingly, this is approximately over one-fifth of the figure for elections and there are often five elections per budget. In summary, the political context changes the relationship we study. In particular, elections have a considerable effect on the relationship between political news and bond market activity.

\section{[TABLE 6.]}

As we have already mentioned, the estimated relationships are dynamic, so we are able to consider the impact of individual budgets and elections on co-movement. Figure 1 illustrates the impact of each individual campaign and budget period on the co-movement of political news and bonds. Most of them are not associated with co-movement, 14 of 34 are statistically significant. Elections tend to have the greatest impact and most of them are associated with co-movement: four of the six elections are among the episodes that had the largest impact, namely the elections in $2010,2001,2005$, and 1997 . The 2010 election had the greatest positive impact - a 1.42 standard deviation increase in co-movement - followed closely by 2001, 1987 and 2005. The direction of the sign indicates that political news activity is associated with an increase in market activity, and 
vice versa. In each case, the pre-election polls were largely accurate; the Conservative Party maintained a strong lead in the polls in 1987, the Labour Party did the same in 2001 and 2005, and the polls predicted correctly a 'hung parliament' in $2010 .^{7}$ A hung parliament is where no single party holds an absolute majority of seats and there have been only a handful in recent British history.

Budgets matter too, but not as much as elections: 10 of 28 are statistically significant. The 2006, and 1993 budgets, both post-election budgets, are associated with some of the largest positive increases in co-movement between bonds and political news. However, most of the statistically significant budgets (six of 10) are associated with a reduction in co-movement. The 1997 budget was associated with the largest reduction. On balance, elections matter more often than not and about one third of budgets matter.

\section{[FIGURE 1.]}

\section{Bank of England Announcements and Macroeconomic Policy News}

We found a strong relationship between news about political competition and market activity over a long time period. However, it would be a mistake to assume that other types of media coverage don't matter. Under some conditions, economic policy news may lead to more variations in market activity. After 1997, the Bank of England was given operational independence over monetary

\footnotetext{
${ }^{7}$ In 2005, the Labour Party's support was somewhat reduced but it was still clearly leading the polls throughout the campaign. The main beneficiary of Labour's reduced support was a third party, the Liberal Democrats, whose substantial gains in the polls could not easily be translated into seats due to the UK's majoritarian political system.
} 
policy, giving it a greater degree of influence and input into monetary policy decisions. As a consequence, we should observe a greater role for macroeconomic policy news after 1997, as both investors and the media should pay close attention to the Bank's Monetary Policy Committee (MPC) - a small group of technocrats, who are responsible for voting on what monetary policy action to take.

Like central banks elsewhere, the Bank of England has procedures to limit volatility around interest rate decisions. One particular strategy is 'forward guidance', where the Bank signals the likely future course of monetary policy well ahead of the formal announcement. Another is strict limitations on what MPC members can say about monetary policy in public, limiting the potential for information leakages that might move markets. These features of modern central banking pose a challenge for empirical research. If 'forward guidance' is successful, we should observe little difference around formal interest rate announcements, as the outcome has already been expected.

Of course, forward guidance is not the only source of information that investors use, and central banks certainly are not infallible or entirely insulated from politics. Indeed, de jure central bank independence is not always de facto independence, and the broader socio-political conditions and changing discourse that laid the foundation for central bank independence must also be acknowledged. These changes include a shift to New Labour and preparations elsewhere for EMU in many EU member countries, which may also have had implications for British capital markets. While the technocrats in the central bank may have enjoyed an added layer of insulation from political decision-making after 1997, these broader trends were likely at work simultaneously, on investors, bankers, and politicians. 
To address the empirical challenge of understanding investors' reactions to technocratic, as opposed to political, events we use data from Melvin et al. (2009), who classify Bank of England announcements according to whether the outcome was a surprise or expected. ${ }^{8}$ Their data consist of 126 meetings over a 10 year period. Using their announcement data, we find that co-movement is 1.79 per cent less than the sample average on the day of MPC meetings where the outcome was largely expected by financial markets. By contrast, co-movement is 6.5 per cent greater than the sample average following meetings where the outcome was a surprise. In sum, there is a large 8.29 per cent gap in co-movement between typical meetings and meetings where the outcome was a surprise. Overall, these findings show while the Bank of England's communications strategy works most of the time, as MPC meetings are typically associated with less co-movement, technocratic decisions are monitored very closely and prompt substantial media and market reactions when they differ from expectations. Macroeconomic policy news moves markets when political competition is not relevant to policy. In other words, policy news matters more when the decision-makers are technocrats.

In the Supporting Information we explore the impact of selected shocks on co-movement, finding that a series of political events including election surprises, shock changes in leadership, the independence of the Bank of England, and the global financial crisis, amplified the relationships we have observed. These case studies exhibit the face-validity of our method. If there was no correlation around these events, we would be concerned about our measures. These studies

\footnotetext{
${ }^{8}$ The authors classify decisions as a surprise if the outcome of the MPC meeting differs from the median expectation taken from a survey of market economists by Bloomberg (Melvin et al., 2009, p. 17).
} 
also show that markets are following the news in order to be able to react to idiosyncratic situations and do not employ bland models. We are encouraged that our dataset provides the basis for a general argument about the primacy of political news, as well as a rich source for further study of specific events and periods.

\section{[TABLE 7.]}

\section{Conclusion}

The extent to which markets monitor politics in advanced economies is an unresolved question in political economy. Our contribution to this debate emphasizes the need to rethink political risk in advanced economies. Theoretically, we emphasise that markets are dynamic and volatile and that political competition is a particular opportunity for investors, since it precedes economic policy and is difficult to interpret. Empirically, we have supported this argument using a valid and reliable measure of political competition that can be implemented on virtually unlimited amounts of text. We show that markets are interested in politics, not just macroeconomic statistics. Moreover, we show that market interest is not confined to elections or other specific events but varies daily over several decades.

Nonetheless this finding has some limitations and thus our argument must be qualified. We do not distinguish between different types of political risk. Thus, we cannot say whether electoral risk, or another type of political risk, is the root cause of the tension between markets and democratic politics. Moreover, we cannot dismiss central bank influence, as we find that it strongly amplifies the link between economic policy news and market behaviour. This is perhaps best typified by the reaction to Mario Draghi's “whatever it takes” speech in July 2012, and reactions to central interventions immediately following the global pandemic of 2020 . 
The substantive implication of our finding is that developed democracies such as the UK may not have as much room to manoeuvre as the strong-but-narrow thesis implies. The illusion that such countries are somehow immune from political risk in the eyes of markets reflects a number of developments over the last few decades including the spread of an anti-inflation ideology, a more general macroeconomic consensus between left and right, and more stable energy supplies. However, recent landmark events underscore the need for a broader view of political risk. The political consequences of the euro crisis, Brexit, and the global pandemic, as well as the rise of populist and far right leaders in Europe and elsewhere, suggest that political change will remain a source of uncertainty for the foreseeable future. 


\section{References}

Afonso, A., and Strauch, R., 2007. Fiscal policy events and interest rate swap spreads: Evidence from the EU. Journal of International Financial Markets, Institutions and Money, 17(3), 261-276.

Archer, Candace C., Biglaiser, G., and DeRouen, K., 2007. Sovereign bonds and the 'democratic advantage': Does regime type affect credit rating agency ratings in the developing world? International Organization, 61(2), 341-365.

Baumgartner, F., Green-Pedersn, C., and Jones B.D., 2006. Comparative Studies of Policy Agendas. Journal of European Public Policy, 13(7), 959-974.

Beaulieu, E., Cox, G.W., and Saiegh, S., 2012. Sovereign debt and regime type: Reconsidering the democratic advantage. International Organization, 66(4), 709-738.

Bechtel, M.M., and Füss, R., 2008. When Traders Enjoy Less Policy Risk: Divided Government, Economic Policy Change, and Stock Market Volatility in Germany, 1970-2005. Swiss Political Science Review, 14(2), 287-314.

Bechtel, M.M., 2009. The Political Sources of Systematic Investment Risk: Lessons from a Consensus Democracy. Journal of Politics, 71(2), 661-77.

Bernoth, K., Von Hagen, J., and Schuknecht, L., 2004. Sovereign Risk Premia in the European Government Bond Market. ECB Working Paper, No. 369.

Bernhard, W., and Leblang, D., 2006, Democratic processes and financial markets: Pricing politics. Cambridge: Cambridge University Press. 
Biglaiser, G., Staats, J. L., 2012. Finding the 'democratic advantage' in sovereign bond ratings: the importance of strong courts, property rights protection, and the rule of law. International Organization, 66(03), 515-535.

Bølstad, J., Elhardt, C., 2018. Capacity, Willingness, and Sovereign Default Risk: Reassuring the Market in Times of Crisis. Journal of Common Market Studies, 56(4), 802-817.

Bølstad, J., and Elhardt, C., 2015. To bail out or not to bail out? Crisis politics, credibility, and default risk in the Eurozone. European Union Politics, 16(3), 325-346.

Breen, M., and McMenamin, I., 2013. Political institutions, credible commitment, and sovereign debt in advanced economies. International Studies Quarterly, 57(4), 842-854.

Courtney, M., Breen, M., McMenamin, I., and McNulty, G., 2020 Automatic Translation, Context, and Supervised Learning in Comparative Politics. Journal of Information Technology and Politics, https://doi.org/10.1080/19331681.2020.1731245

De Bondt, W. and Thaler, R., 1985. Does the Stock Market Overreact? Journal of Finance, 43 (3), 793-805.

DiGiuseppe, M., and Shea, P.E., 2015. Sovereign Credit and the Fate of Leaders: Reassessing the 'Democratic Advantage'. International Studies Quarterly, 59(3), 557-570.

Engle, R., 2002. Dynamic conditional correlation: A simple class of multivariate generalized autoregressive conditional heteroskedasticity models. Journal of Business \& Economic Statistics, 20(3), 339-350.

Goldbach, R. and Fahrholz, C., 2011. The Euro Area's Common Default Risk. Evidence on the Commission's Effect on Uncertainty. European Union Politics, 12(4), 507-28. 
Hallerberg, M., and Wolff, G.B., 2008. Fiscal institutions, fiscal policy and sovereign risk premia in EMU. Public Choice, 136(3-4), 379-396.

Hallin, D. and Mancini, P., 2004, Comparing media systems: Three models of media and politics. Cambridge: Cambridge University Press.

Hardie, I., Henderson, A. and Rommerskirchen, C., 2019. The Impact of Treasury Yields on US Presidential Approval, 1960-2010. New Political Economy, DOI: 10.1080/13563467.2019.1680962.

Hillard, D., Purpura, S., and Wilkerson, J., 2007. Computer-Assisted Topic Classification for Mixed-Methods Social Science Research, Journal of Information Technology and Politics, 4(4), 31-46.

Jayachandran, S., 2006. The Jeffords Effect. Journal of Law and Economics, 49(2), 397-425.

Jennings, R. and Starks, L., 1985. Information content and the speed of stock price adjustment. Journal of Accounting Research, 23(1), 336-350.

Kaid, L.L., and Strömbäck, J., 2008. Election news coverage around the world: A comparative perspective. The handbook of election news coverage around the world, 421-431.

Kahneman, D. and Tversky, A., 1979. Prospect Theory: An Analysis of Decision Under Risk. Econometrica, 47 (2), 263-291.

Katzenstein, P., 1985. Small States in World Markets: Industrial Policy in Europe, Ithaca, Cornell University Press. 
Krippendorff, K., 2004. Content Analysis: An Introduction to its Methodology. 2nd. ed. London: Sage.

Leblang, D., and Mukherjee, B., 2005. Government Partisanship, Elections, and the Stock Market: Examining American and British Stock Returns, 1930-2000. American Journal of Political Science, 49(4), 780-802.

Manning, C. D., Raghavan, P., Schütze, H., 2008. Introduction to Information Retrieval. Cambridge: Cambridge University Press.

McMenamin, I., Breen, M., and Muñoz-Portillo, J., 2016. Comparative Politics and QuasiRational Markets. New Political Economy, 21 (6), 587-605.

Mosley, L., 2003. Global Capital and National Governments. Cambridge: Cambridge University Press.

Melvin, M. and Saborowski, C., Sager, M., Taylor, M.P., 2009. Bank of England Interest Rate Announcements and the Foreign Exchange Market. CESifo Working Paper Series No. 2613. Available at SSRN: https://ssrn.com/abstract=1392156,

Rodrik, Dani. 1997. "Has globalization gone too far?” California Management Review 39(3): 2953.

Rommerskirchen, C., 2015. Debt and punishment: market discipline in the Eurozone. New Political Economy, 20(5), 752-782.

Rommerskirchen, C., 2019. EU Fiscal Policy Coordination in Hard Times: Free Riders on the Storm. Oxford: Oxford University Press. 
Sattler, T. 2013. Do Markets Punish Left Governments? Journal of Politics, 75(2), 343-356.

Scheinkman, J.A., Arrow, K., Bolton, P., Grossman, S., and Stiglitz, J., 2014. Speculation, Trading, and Bubbles. New York: Columbia University Press.

Shiller, R.J., 1995. Conversation, Information, and Herd Behavior. American Economic Review, 85(2), 181-185.

Smeets, D. and Zimmermann, M., 2013. Did the EU Summits Succeed in Convincing the Markets during the Recent Crisis? Journal of Common Market Studies, 51(6), 1158-1177.

Vaaler, P.M., Schrage, B.N., and Block, S.A., 2005. Counting the investor vote: Political business cycle effects on sovereign bond spreads in developing countries. Journal of International Business Studies, 36(1), 62-88. 


\section{TABLE 1. Inter-coder Agreement Tests}

\begin{tabular}{ll}
\hline Coding Scheme & Score \\
\hline Political Competition, Macroeconomic, Microeconomic, Other Policy, Other & 0.75 \\
Political Competition, Macroeconomic, Microeconomic, Other & 0.73 \\
Political Competition, Economic Policy, Other Policy, Other & 0.8 \\
Political Competition, Economic Policy, Other. & 0.79 \\
\hline
\end{tabular}

Note: Coefficients are Krippendorff's Alpha among three coders. The data are 300 randomly selected Financial Times paragraphs.

TABLE 2. Classifier Performance by Category for Biased/Unbiased Training Sets

\begin{tabular}{lll}
\hline Category $i$ & Category $i$ & Other \\
\hline Macroeconomic Policy & 0.78 & 0.86 \\
Microeconomic Policy & 0.76 & 0.72 \\
Political competition & 0.71 & 0.89 \\
\hline
\end{tabular}

TABLE 3. Dynamic Correlations - Mean $(y)$

\begin{tabular}{lrrrr}
\hline \multicolumn{1}{c}{$y$} & Estimate & $\begin{array}{c}\text { R. Standard } \\
\text { Error }\end{array}$ & z Statistic & $\begin{array}{c}\text { P } \\
\text { Significance } \\
\text { level }\end{array}$ \\
\hline Returns-Macro & 0.020 & 0.014 & 1.43 & 0.152 \\
Returns-Micro & 0.040 & 0.023 & 1.67 & 0.094 \\
Returns-Polcomp & 0.004 & 0.018 & 0.24 & 0.812 \\
\hline
\end{tabular}

$n=6,855$ 
TABLE 4. Volatility Correlations $(p)$

\begin{tabular}{lrrrr}
\hline \multicolumn{1}{c}{$\rho$} & Estimate & $\begin{array}{c}\text { R. Standard } \\
\text { Error }\end{array}$ & z Statistic & $\begin{array}{c}\text { P } \\
\text { Significance } \\
\text { level }\end{array}$ \\
\hline Returns-Macro & -0.022 & 0.015 & -1.400 & 0.162 \\
Returns-Micro & -0.016 & 0.014 & -1.160 & 0.248 \\
Returns-Polcomp & 0.036 & 0.014 & 2.510 & 0.012 \\
\hline
\end{tabular}

$n=6,855$

TABLE 5. Descriptive Statistics

\begin{tabular}{lccccc}
\hline Variable & Mean & SD & Min & Max & \multicolumn{1}{l}{ Obs } \\
\hline Political co-movement & 0.043 & 0.037 & 0.000 & 0.451 & 6855 \\
Macro co-movement & 0.045 & 0.042 & 0.000 & 0.436 & 6855 \\
Micro co-movement & 0.042 & 0.037 & 0.000 & 0.397 & 6855 \\
Political coverage & 0.246 & 0.038 & 0.052 & 0.999 & 6857 \\
Macro coverage & 0.358 & 0.047 & 0.125 & 0.993 & 6857 \\
Micro coverage & 0.424 & 0.029 & 0.208 & 0.816 & 6857 \\
\hline
\end{tabular}

TABLE 6. Political Context and Volatility $(p)$

\begin{tabular}{lrrr}
\hline \multicolumn{1}{c}{ Variable } & Coefficient & $\begin{array}{c}\text { R. Standard } \\
\text { Error }\end{array}$ & $\begin{array}{c}\text { P Significance } \\
\text { level }\end{array}$ \\
\hline Returns-polcomp & & & \\
Budget & -0.000 & 0.001 & 0.625 \\
Election & 0.025 & 0.005 & 0.000 \\
Returns-macro & & & \\
Budget & -0.005 & 0.001 & 0.000 \\
Election & -0.004 & 0.003 & 0.120 \\
\hline$n=6,855$ & & &
\end{tabular}

TABLE 7. Bank Announcements and Macroeconomic Policy News, 1997 - 2007

\begin{tabular}{lll}
$\begin{array}{l}\text { Monetary Policy } \\
\text { Committee Meeting } \\
\text { Outcome }\end{array}$ & $\begin{array}{l}\text { As a share of sample } \\
\text { average }\end{array}$ & $\begin{array}{l}\text { Difference between MPC } \\
\text { outcomes and sample } \\
\text { average (\%) }\end{array}$ \\
\hline $\begin{array}{l}\text { Expected (107) } \\
\text { Surprise (19) }\end{array}$ & $98.21 \%$ & $-1.79 \%$ \\
\hline
\end{tabular}

Source: Melvin et al. (2009). Number of meetings in parentheses. 
FIGURE 1. Political News and Co-movement

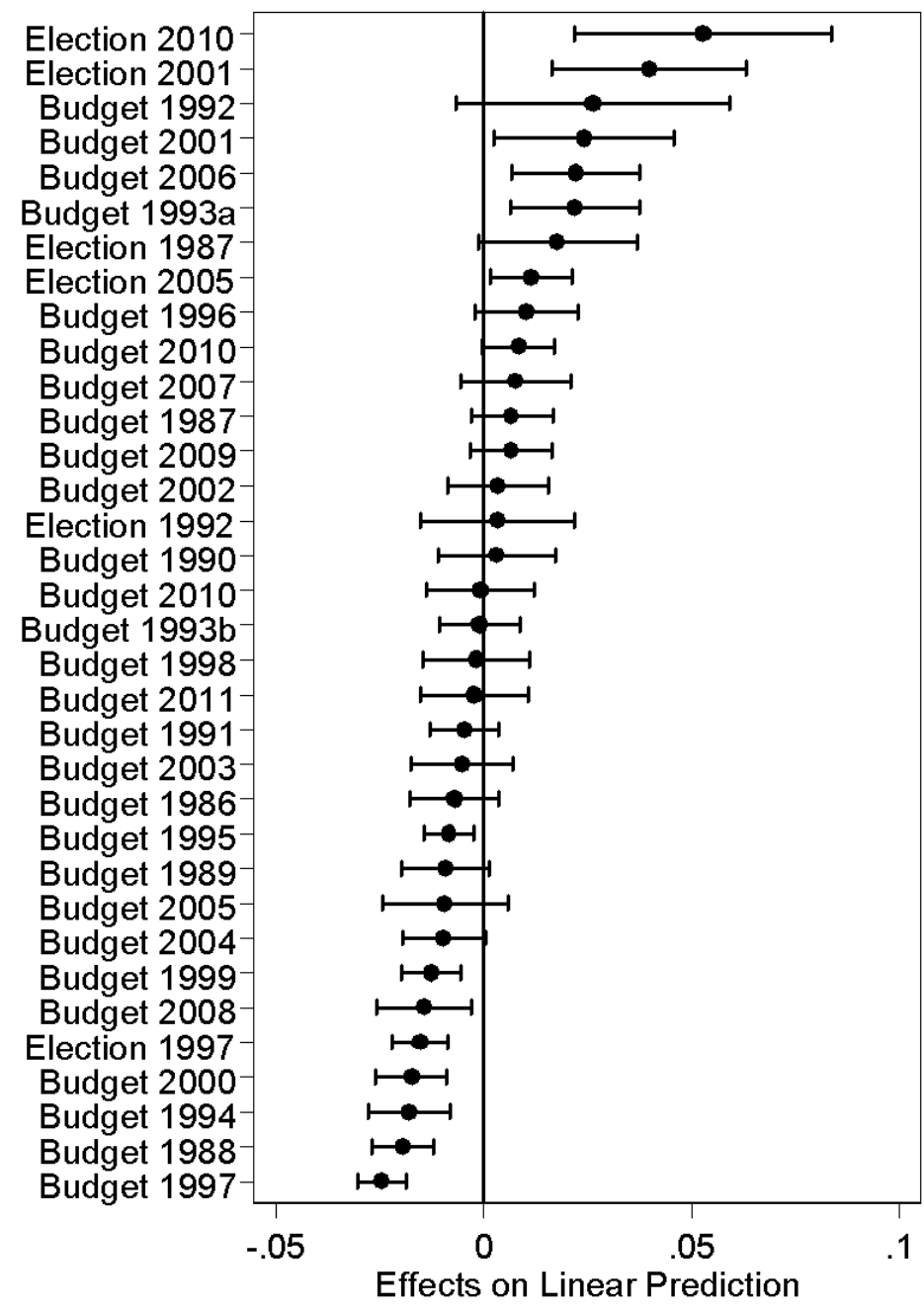

Notes: Linear regression with robust standard errors. $n=6848$. Confidence intervals and illustrated using horizontal lines that are capped at the $95 \%$ upper and lower limits. 


\section{Supporting Information}

FIGURE S1. Human Coding Decision Tree

Primarily politics and/or policy?

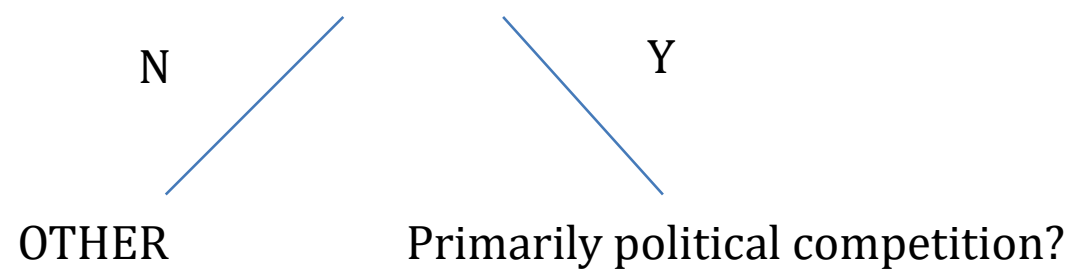

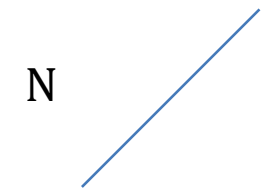

Primarily policy maker or policymaking institution?

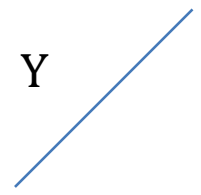

Primarily Economic Policy
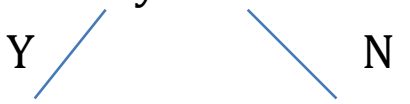

Primarily Macroeconomic OTHER

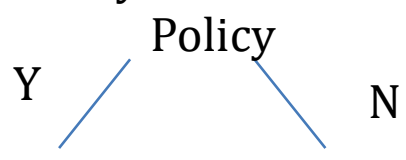

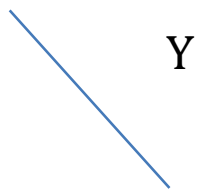

POLITICAL COMPETITION

MACROECONOMIC MICRO

Primarily Economic Policy

POLICY

ECONOMIC POLICY

Primarily policy recommendation and/or preference?

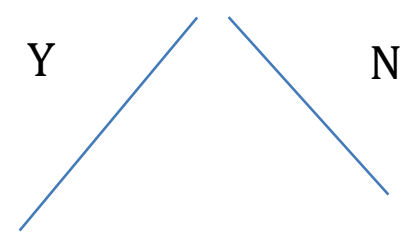

OTHER 


\section{Coding Guidelines}

1. Other 2. Political Competition 3. Economic Policy

\section{General}

- We are coding the primary subject of the text as a whole, not weighting towards a headline or beginning. This means we are coding the topic which has the greatest number of words. We do not take into account headlines or the sequence of topics in the article.

- It is okay to use your own knowledge, for example, whether a name refers to a policy-maker or whether a company is state-owned.

- In the first place use the decision tree; in the second place use these guidelines; if you are still confused refer to the examples in the training set.

- Letters and book reviews should be ignored.

\section{References to Economic Policy}

- If unsure as to whether the topic refers to economic policy, refer to the Comparative Policy Agendas codes. Economic policy refers to, Macroeconomics, Labour and Employment, Banking, Finance and Internal Trade, International Affairs and Foreign Aid (Economic aspects only) and Foreign Trade, but not to social or environmental policy, or other sectors such as education, energy, transport, and communications.

- Industrial policy is classed as macroeconomics according to the policy agendas scheme, even though this appears to be a micro-economic policy. This is not sectoral regulation.

- News on financial market activity is also other, unless there is some discussion of possible or actual official action influencing the markets.

\section{Political Competition Code}

- Political competition refers to strategy, horserace, and personality. It does not refer to governance policies, like the electoral system, minorities, regions, etc. Neither does it refer to defense or security issues.

- Some references to the policies of parties and politicians will be coded as strategy.

- Political corruption is usually political competition. If one party or individual makes any accusation about a rival, individual or party, it is political competition. If a party engages in corruption it is political competition. If there is report on an individual engaged in corruption for personal, not political, gain it is other.

\section{Economic Policy Code}


- If there is some reference to a body with an economic policy-making role, such as the government, legislature, central bank, official commission, then the text should be coded as economic policy. This includes analysis by an official or official body.

- If there is no reference to an official or official body, the text can only be coded as economic policy if there is an expressed economic policy preference or recommendation.

- Court cases: If they have an economic policy implication, they are coded according to that policy. Usually, court cases will be other. 


\section{Supporting Information}

In this section we present a series of additional empirical tests and explore the impact of selected shocks on co-movement. The first three sections explore the impact of selected shocks on comovement through a series of ten short case studies. The fourth section explores patterns in news coverage and co-movement around different types of budgets, including pre-election and postelection budgets. Section five tests the effect of political events on economic policy news, repeating our tests from the main paper using policy news in place of news about political competition. Section six displays our results using an alternative dependent variable, the absolute yield on UK 10-year bonds.

\section{Financial markets and political news: four case studies}

Most of the time, uncertainty about the composition of the legislature and taxation and spending is resolved once the budget or election is over. However, there are occasions when unexpected shocks disrupt the market-media relationship that we have observed so far. Figure 2 illustrates the impact of four unusual episodes on the co-movement of political news and government bonds. In each case, there is a substantial change in co-movement around the release of new information. The first panel illustrates the unexpected victory of the Conservative party in the 1992 general election. As we have already remarked, almost every poll predicted a small majority for the Labour party or a Labour-led hung parliament. The election was called on the $11^{\text {th }}$ of March and it was held on the $9^{\text {th }}$ of April. Figure 2 illustrates two large spikes in co-movement: one before the election was called and the other after the result is announced. The first spike captures speculation in an extremely close race. In accordance with our argument, it is much larger than the second spike, suggesting that there is more money to be made earlier in the political process. The second 
spike captures the impact of surprise regarding the Conservative Party's victory, as investors and the media must digest new information about the composition of the legislature in a very short space of time.

The 2010 general election, depicted in the second panel, is an example of an election result that did not immediately resolve uncertainty about the composition of the government. After the election, political parties negotiated for five days to form a coalition government and a Conservative-Liberal Democrat coalition was the outcome. Co-movement follows a familiar pattern in the period before the election but does not subside when the result is announced on May 12, remaining approximately 4 standard deviations above the sample mean during the coalition talks. When the new government is announced on May 12, it decreases.

The third and fourth panels depict the 1990 and 1995 Conservative Party leadership contests. In both cases, the incumbent party leader was also the Prime Minister. Therefore, the contest was for a new head of government and probably a full cabinet reshuffle too, as new leaders usually change some of the ministers in their cabinet.

The leadership contest of 1990 was a surprise because the incumbent Prime Minister, Margaret Thatcher, was forced to resign after the first ballot. There is a notable spike in comovement several days before the first ballot. After the result of the first ballot it rises again in advance of Thatcher's resignation. The idiosyncratic rules of the Conservative Party stipulate that a second ballot is necessary to appoint a new leader. John Major was elected unopposed after the second ballot. Co-movement subsided and did not move dramatically in the run-up to Major's victory and only increased significantly in the days afterward.

The leadership contest of 1995 was different because there was no period when the country was effectively leaderless. The incumbent Prime Minister, John Major, resigned as leader of the 
Conservative Party on the $22^{\text {nd }}$ of June. Rather than being forced to resign like his predecessor, the Prime Minister announced the contest at an opportune moment in order to face down his critics within the party. After the announcement, we observe a substantial spike in co-movement, as more volatile political news is associated with more volatile bond prices. The impact of the announcement tapers off before the leadership election. Following the election, and John Major's victory on the $4^{\text {th }}$ of July, there is another large spike in co-movement, before it drops again. The earlier spike is larger than the later spike, again suggesting that there is more money to be made earlier in the political process.

In summary, changing political contexts can help to us to understand the impact of political competition on the evolution of media-market relations. In the cases we have studied, political news has provoked anticipation, surprise, and uncertainty. In 1990, 1992, and 1995, there is a mixture of anticipation and surprise. In 2010, there is short-lived uncertainty. The majoritarian nature of the British political system has made it easier to study anticipation and surprise, both of which tend to be less dramatic in gradualist, consensual systems.

\section{[FIGURE S2.]}

\section{Financial markets and economic policy news: four case studies}

In this section, we consider four episodes from UK economic history which had arguably the greatest short-term impact on the rules underpinning in the UK economy between 1986 and 2012, and one episode that signaled an external rule change with big implications for the UK economy. Figure S3 illustrates co-movement around these episodes. The first panel relates to the United Kingdom's entry to the European Exchange Rate Mechanism (ERM) in 1990. The second panel relates to the 1992 exit from the same, known colloquially as Black Wednesday. The third panel 
illustrates the announcement in 1997 of the independence of the Bank of England. The fourth panel shows the European Central Bank's 2011 announcement of long-term support for the European banking system (LTRO), a pivotal moment in the European debt crisis.

In three of our cases, namely ERM Entry, Black Wednesday, and the ECB's LTRO, the historical record tells us that market and media speculation was rife. Therefore, we expect to observe co-movement before and after each of these three episodes. In one of the cases - Bank of England $(\mathrm{BoE})$ independence - the new institutional arrangement was a closely guarded secret so we do not expect to witness co-movement before the announcement. We expect it after, as markets are forced to react to the new information in a short space of time.

First, we consider is the UK's entry to the ERM in October 1990. ERM was a system of fixed exchange rates and a precursor to Economic and Monetary union. The UK joined when the pro-Europe faction of the Conservative Party dominated government. Within two years, the UK was forced to exit ERM after its currency came under speculative attack and the government could not maintain its value at the agreed level. In the weeks before UK entry, Figure S3 shows a considerable increase in $\rho$. Soon after the announcement there is another sharp increase in $\rho$, which lasts for a few days before returning to normal values. The relationship that we expected - comovement before and after the announcement is evident. Furthermore, there is relatively more comovement beforehand, as evidenced by the area under the curve, supporting our argument that there is more money to be made anticipating important economic information than reacting to the same information when it becomes public knowledge.

In the second panel, we observe broadly the same pattern before and after Black Wednesday. As the UK's exit from ERM approaches, co-movement rises to a high of approximately 0.16 in the days before exit. After the pound's exit co-movement rises again, but 
like the previous panel it does not rise to the same extent as the pre-exit high.

The third panel shows the announcement in 1997 of BoE independence. The reform came as a surprise announcement a few days after the Labour party's election win. As part of the reform, power to decide interest rates was granted to a new monetary policy committee that was largely

independent of political control. For most of the period before the announcement $\rho$ takes values within the normal range for this time series. After the announcement, there is a very large change, from approximately .05 to more than 0.2. As expected, co-movement is not as strong before the announcement, suggesting little co-speculation about the government's policy decision.

The fourth panel illustrates the ECB's 2011 announcement of a loan scheme for European banks. As the European debt crisis unfolded, there was increasing uncertainty about the commitment of the ECB to the euro currency. These fears were addressed in a series of ECB statements and policy actions, beginning in 2011. Arguably the most important of these was the announcement on December 8th of the LTRO (LTRO). The facility pledged low interest threeyear loans totaling 489.2 billion euro to support European banks. In the month before the scheme, we observe a large spike in co-movement, followed by smaller spikes later in the month and around the day itself. The large spike appears similar to Black Wednesday, and is in line with arguments that stress the link between macroeconomic policy news and financial market activity.

\section{[FIGURE S3.]}

\section{The global financial crisis of 2007-2009}

In this section, we consider the impact of two key episodes during the global financial crisis. The first is the collapse of the US investment bank Lehman Brothers and the subsequent 700-billion- 
dollar bank rescue orchestrated by the US government. This is perhaps the defining moment of the crisis and one of the most important episodes in world economic history. While it occurred outside of the United Kingdom, we expect an increase in co-movement, as markets and the media respond to shocks outside the UK with variations in prices and media coverage.

In Figure S4, we illustrate variation in co-movement around these events. As expected, there is a substantial increase on the day of Lehman's collapse, several times greater than the sample average. The graph shows an even sharper increase in the days when the US authorities were negotiating a rescue package to bailout the other investment banks that were exposed to the crisis. The largest spike is on September $23^{\text {rd }}$, as news began to emerge that the US authorities were close to agreeing a workable plan; the final 700-billion-dollar bailout was announced on September $28^{\text {th }}$. This episode illustrates the potential for events outside of the United Kingdom to influence UK markets and media, as there was a substantial increase in co-movement around these historic events.

The second key episode we consider is the failure of Northern Rock bank in 2007, which prompted the first UK bank run since $1866 .{ }^{9}$ Although this episode is specific to the United Kingdom, it can be seen as a manifestation of the wider financial crisis in global markets. In 2007, Northern Rock was highly exposed to these markets - approximately $70 \%$ of its total funding came from wholesale markets. ${ }^{10}$ As they dried up, the bank experienced a severe liquidity crisis. When news of its weakness spread, customers panicked and withdrew $40 \%$ of their deposits in a short amount of time, forcing the UK government to step in to prevent the crisis spreading to other institutions. On the $1^{\text {st }}$ of October 2007, the government announced that UK savings deposits

\footnotetext{
${ }^{9}$ Shin, H. (2009). Reflections on Northern Rock: The Bank Run That Heralded the Global Financial Crisis. The Journal of Economic Perspectives, 23(1), 101-120. Retrieved from http://www.jstor.org/stable/27648296 ${ }^{10}$ Martin Arnold AUGUST 31, 2017. Northern Rock in facts and figures. The Financial Times. Available online at https://www.ft.com/content/5bf237e6-8d0e-11e7-a352-e46f43c5825d
} 
would be guaranteed up to $£ 35,000$. In line with our findings regarding the collapse of Lehman's and subsequent US government bailout, there is a substantial increase in co-movement around these important events. Indeed, the scale of the reaction to these events is comparable to the media and market reactions following the collapse of Lehman's and the subsequent US government bailout.

\section{[FIGURE S4.]}

\section{Types of budgets}

British governments usually present five budgets to parliament and not every budget is the same. The more budgets a government has presented, the less new information the markets expect. Therefore, we expect to observe more co-movement in post-election budgets because the media should speculate more about the budget of the new government, including the possible reaction of the markets. Furthermore, government is under more political pressure and has a shorter time horizon in the budget before an election. Indeed, political business cycle theory has argued that governments may try to "buy the election". Therefore, we expect that pre-election budgets are subject to extra attention from the FT and from the markets, who will be watching each other more closely. In particular, there should be more emphasis on the political strategy, as opposed to the economic rationale, behind the budget. As a consequence, budgets before elections should demonstrate a closer relationship between the volatility of news coverage and markets.

In Table S1, we describe the value of $p$ and the balance of news coverage around different types of budgets. We find that pre-election budgets are associated with substantially more comovement (29 per cent more) than the typical budget, defined as the mean value of co-movement 
during all budgets in our sample. Post-election budgets are associated with slightly less comovement (7.3 per cent). Furthermore, the ratio of political to macroeconomic news coverage is higher in pre-election budgets, relative to both normal budget periods and mean coverage in the sample.

In summary, political events tend to reduce macroeconomic policy-bond market comovement, a finding which runs counter to the macroeconomic school.

\section{[TABLE S1.]}

\section{[TABLE S2.]}

\section{Political context and macroeconomic policy co-movement}

Figure S5 shows the impact of political context on the co-movement of macroeconomic policy news and bonds. It shows that most political events are not associated with co-movement: only 14 out of 33 events are statistically significant. However, of the events that are significant, the vast majority (13 of 14) are associated with a reduction in co-movement. This stands in contrast to the impact of political events on political news co-movement, which exhibits more diversity. Of the significant events, we see a mixture of budgets and elections. Markets and macroeconomic policy news are less likely to move simultaneously in the month before these events. The only exception is the 1993 budget, which aimed to deal with the consequences of the pound's exit from ERM through fiscal consolidation. In this case, the pre-budget period is associated with a large increase in co-movement.

\section{[FIGURE S5.]}

\section{Alternative dependent variable}


Table S3 below substitutes our dependent variable - the spread against US treasury notes with the absolute yield on UK 10-year bonds. As you can see, the results are broadly similar. The political competition coefficient is statistically significant and the relationship is of a similar magnitude (12.5\% less) when compared to its relationship to the spread.

[Table S3.] 
Supplementary Tables and Figures

TABLE S1 Budget types and co-movement

\begin{tabular}{lcrrr} 
Budget type & $\begin{array}{c}\text { Political } \\
\text { News }\end{array}$ & $\begin{array}{c}\text { Percent } \\
\text { change }\end{array}$ & $\begin{array}{c}\text { Macro } \\
\text { Policy }\end{array}$ & $\begin{array}{r}\text { Percent } \\
\text { change }\end{array}$ \\
\hline Average budget & 0.041 & & 0.039 & \\
Post-election budget & 0.038 & -7.3 & 0.039 & 0 \\
Pre-election budget & 0.053 & +29 & 0.040 & +2.5 \\
\hline
\end{tabular}

TABLE S2 News coverage and budgets

Ratio of Political to Macroeconomic Coverage

Pre-budget 0.685

Pre-election budget $\quad 0.718$

$\begin{array}{ll}\text { Sample mean } & 0.687\end{array}$

TABLE S3. Volatility Correlations ( $p$ ): Daily Gilt

\begin{tabular}{lrrrr}
\hline \multicolumn{1}{c}{$\rho$} & Estimate & $\begin{array}{c}\text { R. Standard } \\
\text { Error }\end{array}$ & z Statistic & $\begin{array}{c}\text { P } \\
\text { Significance } \\
\text { level }\end{array}$ \\
\hline Returns-Macro & 0.012 & 0.015 & 0.780 & 0.438 \\
Returns-Micro & -0.008 & 0.014 & -0.580 & 0.564 \\
Returns-Polcomp & 0.032 & 0.014 & 2.240 & 0.012 \\
\hline$n=6,855$ & & & &
\end{tabular}


FIGURE S2. Political Context and Co-movement.
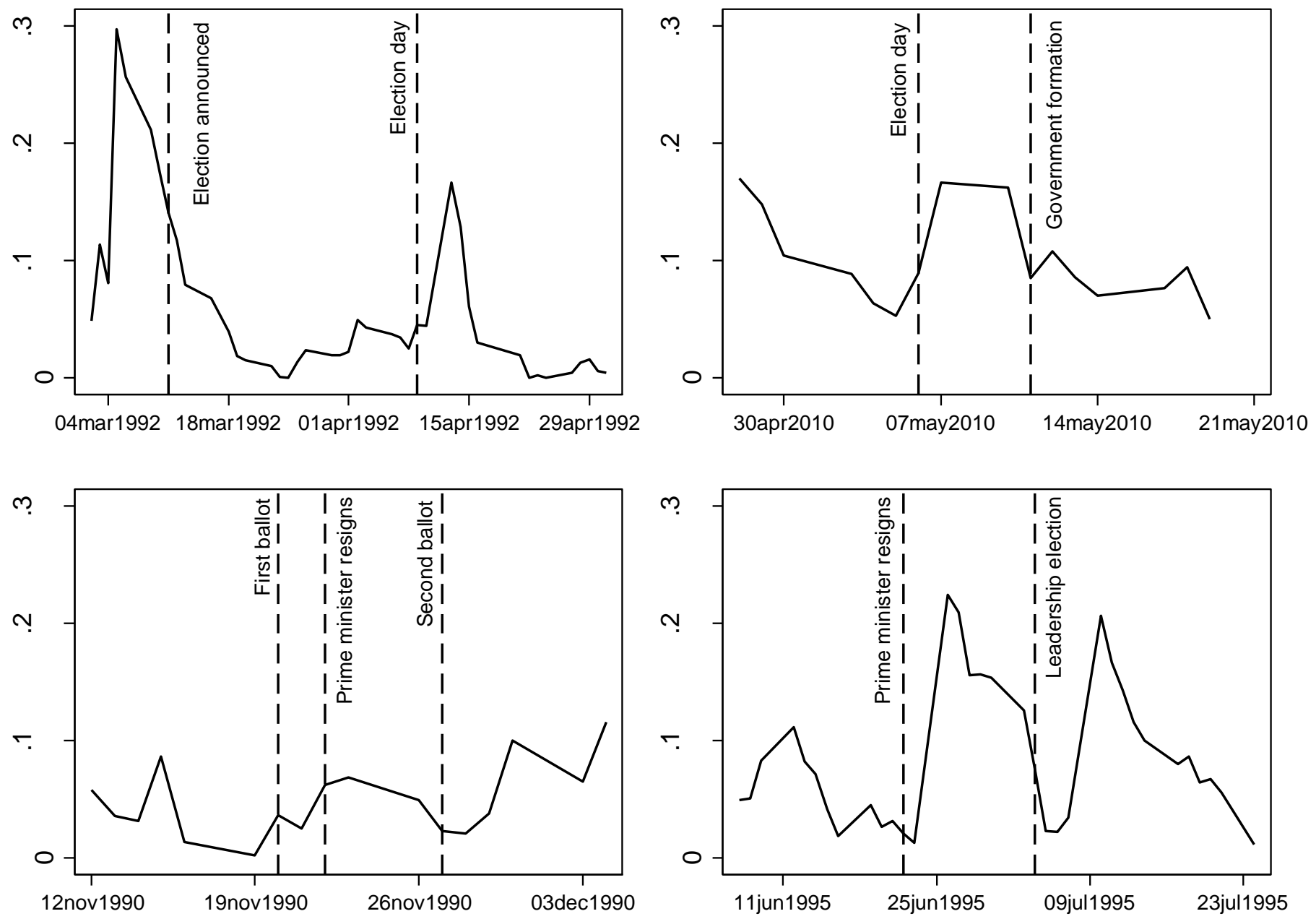

Notes: Panel A relates to the 1992 general election. Panel B relates to the 2010 election. Panel C illustrates the 1990 Conservative Party leadership contest. Panel D illustrates the 1995 Conservative Party leadership contest. 
FIGURE S3. Political Context and Macroeconomic Policy News Co-movement
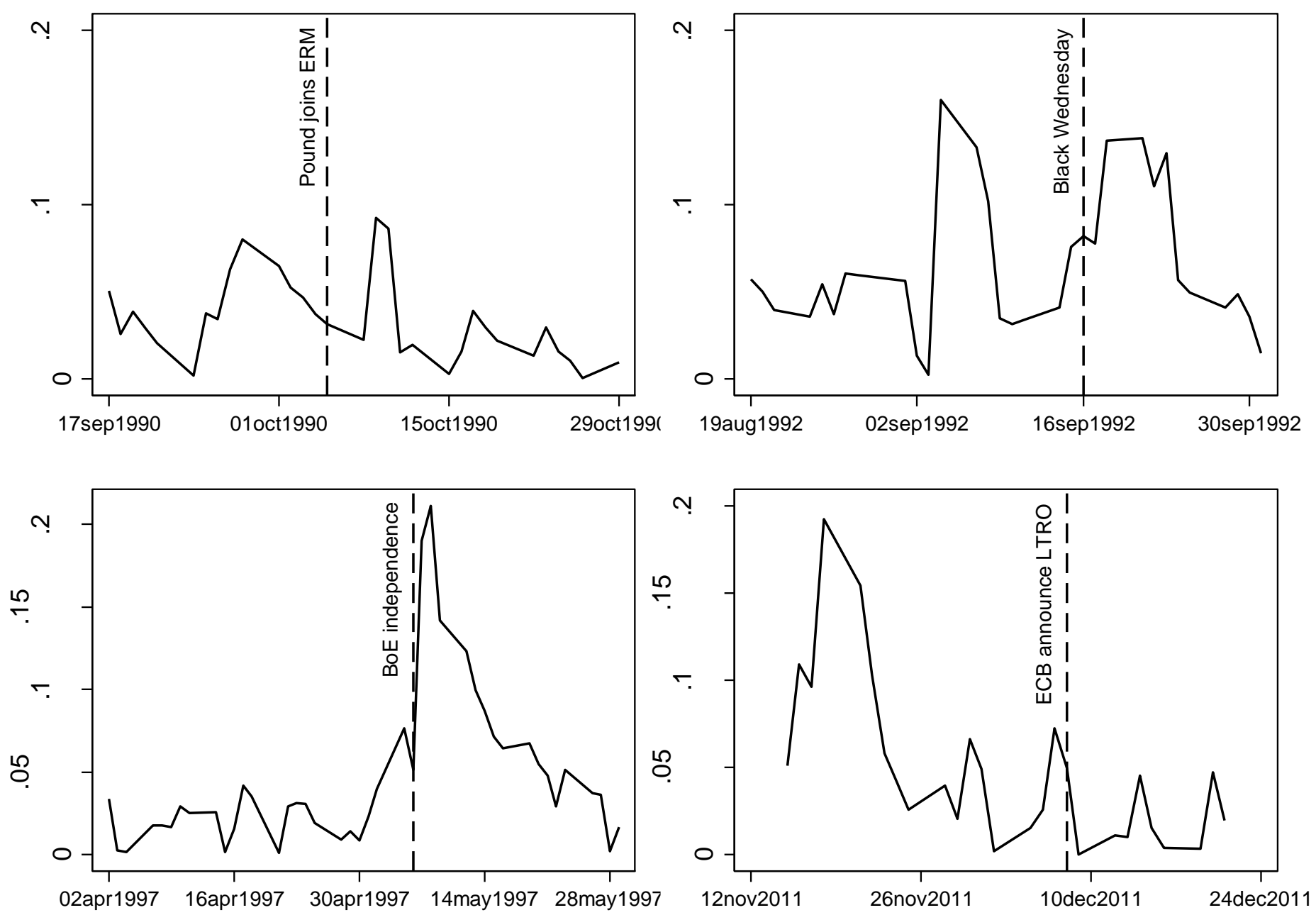

Notes: Panel A relates to the British exit from European Exchange Rate Mechanism (ERM). Panel B illustrates Black Wednesday, 16 ${ }^{\text {th }}$ September 1992. Panel C relates to the announcement of Bank of England independence. Panel D illustrates the announcement of the European Central Bank’s Long-Term Refinancing Operations (LTRO). 
Figure S4. The Global Financial Crisis and Co-movement.

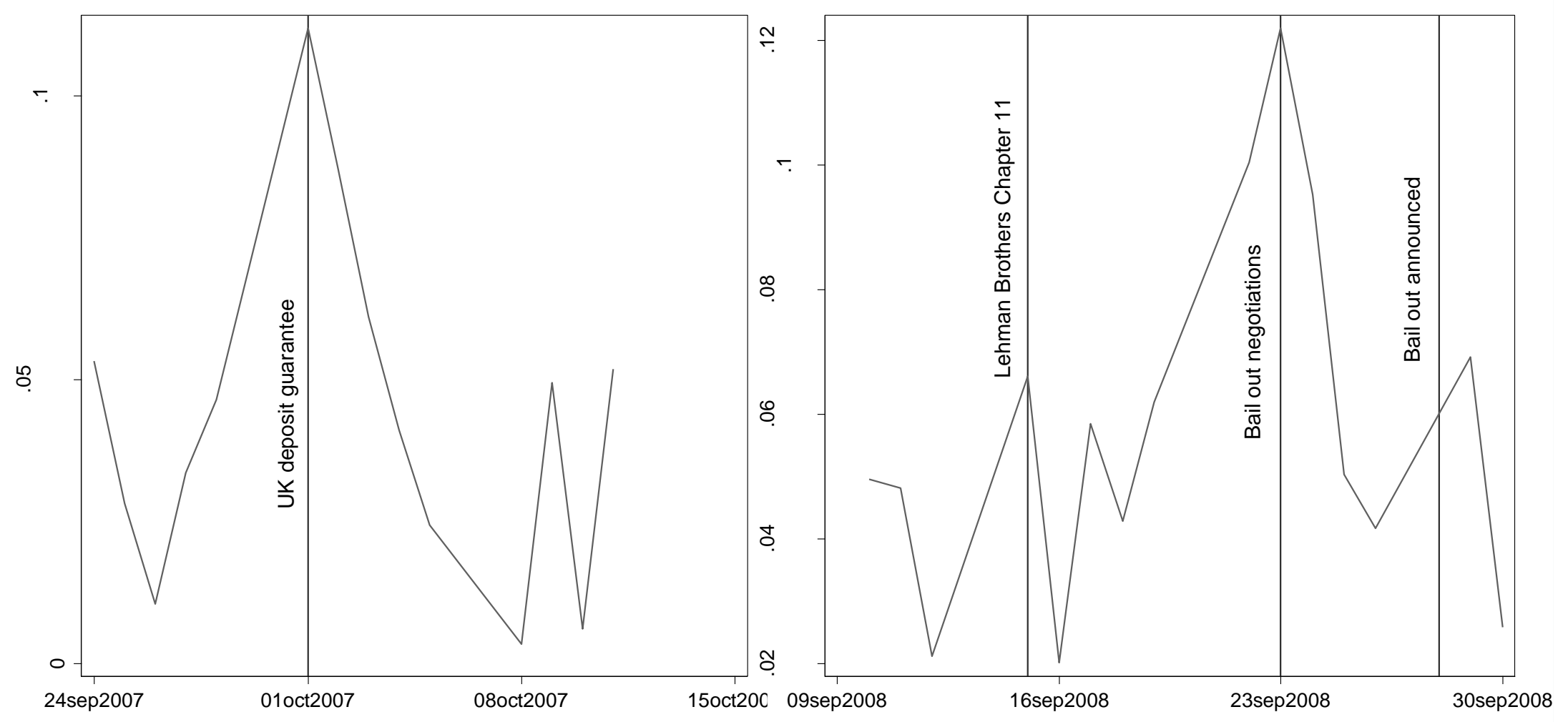

Notes: Panel A illustrates the announcement of the UK savings deposit guarantee. Panel B illustrates three of the key events of the global financial crisis in September 2008. 
Figure S5. Political Context and Macroeconomic Policy Co-movement.

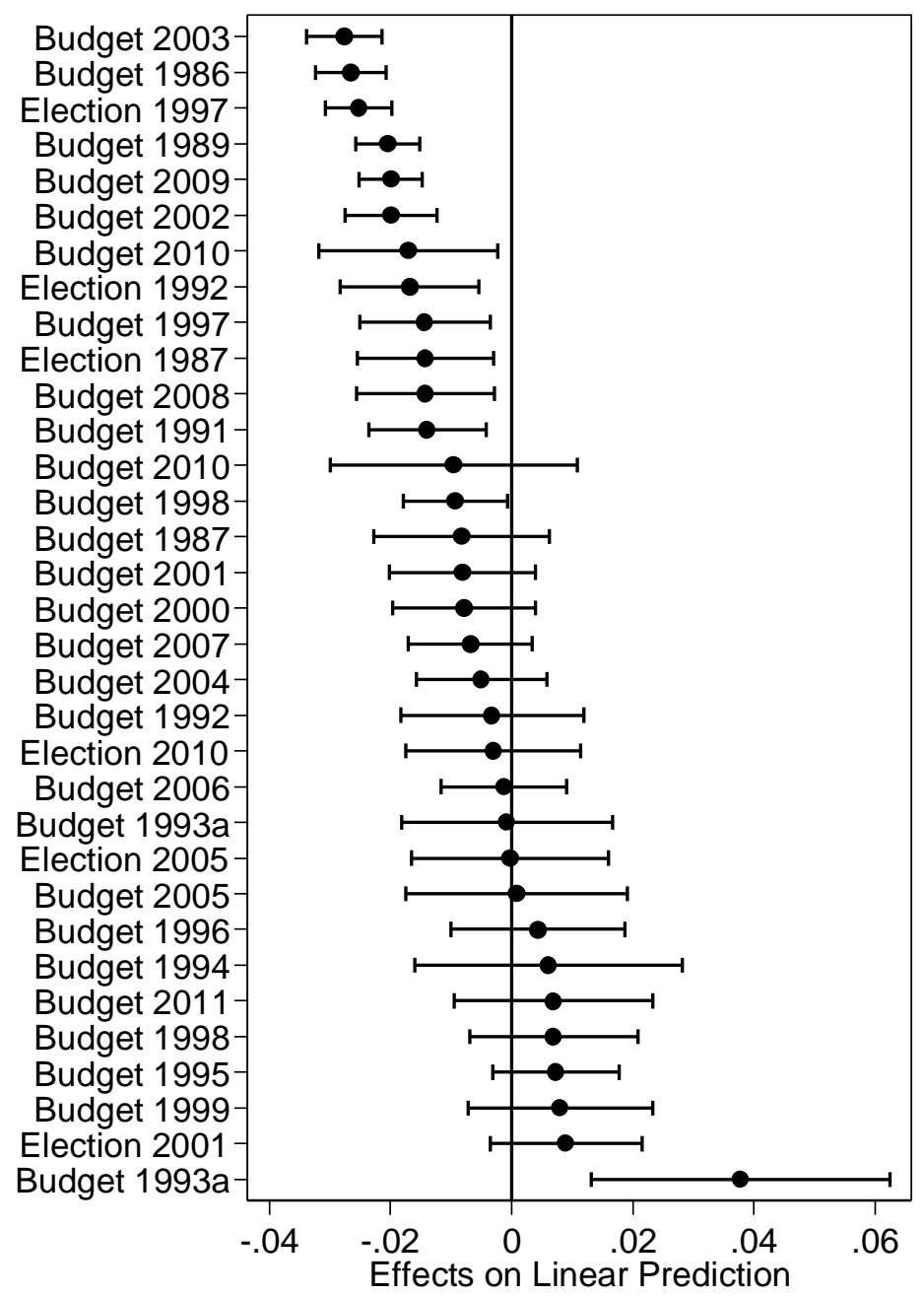

Notes: Linear regression with robust standard errors. $n=6848$. Confidence intervals and illustrated using horizontal lines that are capped at the 95\% upper and lower limits 